\section{Publisher note from Stephanie Hull}

I am delighted to present this special issue focusing on innovation in European aeronautics research and the ideas presented at the 7 th EASN International Conference, an event that I was very fortunate to attend in Warsaw.

As publisher of Aircraft Engineering and Aerospace Technology, it is a pleasure to be able to work with a global network of academics and contribute to the progression of ideas based on reason, quality and scholarly excellence.

This special issue brings together almost 18 months of hard work from Professor Zdobyslaw Goraj and his colleagues. We are extremely thankful for his contribution to the journal.
As well as the eight papers published in this special issue, Professor Goraj kindly worked on five additional papers on this topic that were published earlier in this volume. These were:

1 AEAT-02-2018-0092, "Research and selection of MALE wing profile".

2 AEAT-01-2018-0024, "Conflict-resolution algorithms for RPAS in non-segregated airspace".

3 AEAT-01-2018-0056, "UAV APPLICATION FOR PRECISION AGRICULTURE".

4 AEAT-01-2018-0036, "HYBRIDIZATION OF TRAINING AIRCRAFT WITH REAL WORLD FLIGHT PROFILES".

5 AEAT-01-2018-0070, "MULTIROTOR UAV SENSOR FUSION FOR PRECISION”.

To further showcase this work, these papers will be promoted together and compiled to form a virtual special issue.
The current issue and full text archive of this journal is available on Emerald Insight at: www.emeraldinsight.com/1748-8842.htm

Aircraft Engineering and Aerospace Technology 91/5 (2019) 717

Emerald Publishing Limited [ISSN 1748-8842] [DOI 10.1108/AEAT-05-2019-317] 